\title{
Study of Job Satisfaction and Stress among Doctors from Tertiary Care Institute at Rural Region of Central India
}

\author{
Sachin Ratan Gedam ${ }^{1 *}$, Vijay Babar ${ }^{2}$ and Sneh Babhulkar \\ ${ }^{1}$ Department of Psychiatry, Mahatma Gandhi Institute of Medical Sciences, India \\ ${ }^{2}$ Department of PSM, Jawaharlal Nehru Medical College, India \\ ${ }^{3} \mathrm{MIMH}$ BJ Government Medical College, India
}

*Corresponding author: Dr. Sachin Ratan Gedam, Associate Professor, Department of Psychiatry, Mahatma Gandhi Institute of Medical Sciences, Sevagram, Wardha, Maharashtra, India, Tel: +918983646448, E-mail: sachinrgedam@gmail.com

\begin{abstract}
Introduction: Stress and job dissatisfaction are more among doctors. It can affect their quality of health care.

Objectives: To determine the level of stress and job satisfaction among doctors, to find its association with socio-demographic characteristics and to assess factors affecting job satisfaction.

Methodology: Total 150 out of 176 doctors were selected from tertiary care institute of Sevagram Wardha. Data was collected through socio-demographic proforma, professional characteristics for job satisfaction and kessler10 psychological distress instrument.

Results: Majority (76\%) of doctors were found to be dissatisfied with their job and almost half $(48 \%)$ of them were stressful. Level of stress is negatively correlated with job satisfaction. Doctors were found to be least satisfied with their job on physical working conditions $(2.20 \pm 1.12)$, workload $(2.07 \pm$ $1.09)$, rate of pay and benefits $(2.19 \pm 1.21)$, safety and security $(2.07 \pm 1.11)$, professional growth $(2.19 \pm 1.29)$, autonomy $(2.18 \pm 1.24)$ and adequate resources $(2.14 \pm 1.22)$. The age, marital status, years since graduation and designation were found to be significantly correlated with job satisfaction $(p<0.05)$. Age, marital status and severity of stress were factors affecting job satisfaction.

Conclusion: More than half of doctors (76\%) were not satisfied with their job and more stressful. So, these factors need to be addressed by authority to increase level of satisfaction and improve health care.
\end{abstract}

\section{Keywords}

Doctors, Job satisfaction, Stress, Tertiary care institute, Residents

\section{Introduction}

Stress is defined as physical and psychological state that occurs when the individual is unable to cope with demands and pressure of situation [1]. Job satisfaction is defined as an attitudinal variable that represent the extent to which people dislike or like their jobs [2]. Level of stress and job satisfaction among doctors can affect the quality of health care [3].

The level of job satisfaction is affected by intrinsic and extrinsic factors, social relations with the group, quality of supervision and individual's success or failure in their work [4]. Job security interaction with colleagues, financial incentives and co-operative relationship with management were found to be predictors of job satisfaction among doctors in United States. Whereas opportunities for continuing education, collegial relationships, extent of administrative work, job security and access to specialized technology were contributing factors for satisfaction in Germany [5].

Job satisfaction/dissatisfaction affect one's administration behavior with co-workers and the patients. The doctor-patient relationship and quality of medical care provided is dependent on doctor's job satisfaction [6]. Previous studies reported that $68 \%$ of doctors were unsatisfied with their jobs and females were more dissatisfied as compared to their male counterparts [1]. A study among doctors in Delhi reported that more than half $55.2 \%$ was found to be dissatisfied [7]. 
In other studies, it was found that doctors were more satisfied with autonomy and working environment while clerical workload leads to dissatisfaction [8]. Those working in ambulatory care hospital setting were satisfied as observed by Akroyd and others [9]. A study by Sohag AA, et al. among doctors from teaching institute reported $76.2 \%$ job dissatisfaction with doctors working on lowest posts responded not satisfied with the job [10]. Doctors are considered to be at risk of stress and have higher degree of psychological morbidity, alcohol dependence and suicidal tendencies as compared to comparable social class [11-15].

Doctors are essential and integral component of our healthcare system, job satisfaction is linked to the productivity and quality of services provided by them [7], hence it becomes necessary to assess job satisfaction among doctors. In view of the above finding in literature, its impact on performance of doctors at hospital and healthcare delivery, this study need to be conducted among them. As such there is paucity of research on this topic in our region. The objectives of present study were to find level of job satisfaction and stress among residents and medical faculty of tertiary care institute; to demonstrate association between their overall job satisfaction and socio-demographic characteristics; and to assess factors affecting job satisfaction.

\section{Methodology}

A cross-sectional study was conducted among doctors of Mahatma Gandhi Institute of Medical Sciences, Sevagram from city of Wardha, Maharashtra during March 2018. A total 150 out of 176 doctors who were employed for more 6 months and those involved directly with the patient care were included in the study. They include Post-Graduate students, Senior Residents, Assistant Professor, Associate Professor and Professors. Interns, doctors employed for less than 6 months, preclinical and para-clinical faculties who were not directly involved with the patient care provision were excluded from survey. They were explained about the nature and purpose of study; and information was collected through questionnaires mailed to them. A reminder was sent after a week to those who didn't respond. The approval was obtained from institutional ethics committee and data was collected using the following tools.

\section{Socio-demographic proforma}

It includes age, gender, marital status, year since graduation, educational status, designation and average number of patients seen per week.

\section{Professional characteristics for job satisfaction}

These are most frequently identified characteristic related to job satisfaction. It includes 10 variables: physical working condition, working relations with colleagues, recognition and motivation, safety and security, workload, professional growth and development, pay and benefits, opportunity to use skills and ability, autonomy and adequate resources. The responses are graded on 5-point likert scale $(1=$ very low to $5=$ very high $)$. This was adopted from a study done by Khuwaja, et al. [3]. The cronbach's alpha reliabilities for variables were found to be 0.894 with $p$-value 0.0001 which is significant and reliable.

\section{Kessler10 psychological distress instrument (k10)}

Developed by Kessler and colleagues. This instrument has been used widely to measure current (1-month) distress, to measure the level of stress and severity associated with psychological symptoms in population surveys. The $k 10$ consists of 10 questions in the form of "how often in the past month did you feel ..." And offers specific symptoms, such as 'tired out for no good reason', 'nervous', and 'sad or depressed'. The five possible responses for each question range from 'none of the time' to 'all of the time' and were scored from 1 to 5 respectively. All the questions were collated to obtain a total score. The total score was interpreted as follows: a score of less than 20 was considered not to represent stress of any level while a score of 20-24

Table 1: Socio-demographic variables of study participants.

\begin{tabular}{|c|c|c|}
\hline Variables & $\begin{array}{l}\text { Number } \\
(n=100)\end{array}$ & $\begin{array}{l}\text { Percentage } \\
(\%)\end{array}$ \\
\hline \multicolumn{3}{|l|}{ Age Group (yrs) } \\
\hline $20-29$ yrs & 79 & 52.67 \\
\hline $30-39$ yrs & 55 & 36.67 \\
\hline $40-49$ yrs & 12 & 8.00 \\
\hline $50-59$ yrs & 4 & 2.67 \\
\hline \multicolumn{3}{|l|}{ Gender } \\
\hline Male & 69 & 46.00 \\
\hline Female & 81 & 54.00 \\
\hline \multicolumn{3}{|l|}{ Marital Status } \\
\hline Single & 72 & 48.00 \\
\hline Married & 78 & 52.00 \\
\hline \multicolumn{3}{|c|}{ Years of experience } \\
\hline$<10$ years & 34 & 22.67 \\
\hline$\geq 10$ years & 116 & 77.33 \\
\hline \multicolumn{3}{|l|}{ Educational status } \\
\hline MBBS Only & 19 & 12.67 \\
\hline PG Diploma & 30 & 20.00 \\
\hline MD/MS & 101 & 67.33 \\
\hline \multicolumn{3}{|c|}{ Working Status (Designation) } \\
\hline PG Students & 61 & 40.67 \\
\hline Senior Residents & 32 & 21.33 \\
\hline Asst. Prof & 39 & 26 \\
\hline Asso. Prof & 11 & 7.33 \\
\hline Professor & 7 & 4.67 \\
\hline \multicolumn{3}{|c|}{$\begin{array}{l}\text { Average number of patients } \\
\text { seen per day }\end{array}$} \\
\hline$\leq 10$ & 32 & 21.33 \\
\hline $11-50$ & 61 & 40.67 \\
\hline$>50$ & 57 & 38.00 \\
\hline
\end{tabular}

Table 2: Distribution of subjects according to overall job satisfaction level.

\begin{tabular}{|l|l|l|}
\hline Overall (Mean) & No of patients & Percentage \\
\hline$\leq 30$ & 114 & 76.00 \\
\hline$>30$ & 36 & 24.00 \\
\hline Total & 150 & 100 \\
\hline
\end{tabular}


Table 3: Distribution of subjects according to Professional characteristics.

\begin{tabular}{|c|c|c|c|c|c|}
\hline Professional characteristics & $\mathbf{N}$ & Minimum & Maximum & Mean & SD \\
\hline Physical working conditions & 150 & 1.00 & 5.00 & 2.20 & 1.12 \\
\hline Working relation with colleagues and fellows & 150 & 1.00 & 5.00 & 3.46 & 0.57 \\
\hline Recognition and motivation & 150 & 1.00 & 5.00 & 3.32 & 0.68 \\
\hline Safety and security & 150 & 1.00 & 5.00 & 2.07 & 1.11 \\
\hline Workload & 150 & 1.00 & 5.00 & 2.07 & 1.09 \\
\hline Rate of pay and benefits & 150 & 1.00 & 5.00 & 2.19 & 1.21 \\
\hline Opportunity to use skills and ability & 150 & 1.00 & 4.00 & 3.17 & 0.63 \\
\hline Professional Growth & 150 & 1.00 & 5.00 & 2.19 & 1.29 \\
\hline Autonomy & 150 & 1.00 & 5.00 & 2.18 & 1.24 \\
\hline Adequate Resources & 150 & 1.00 & 5.00 & 2.14 & 1.22 \\
\hline Overall & 150 & 12 & 43 & 25.02 & 7.55 \\
\hline
\end{tabular}

Table 4: Severity of stress among study participants and its correlation with overall job satisfaction.

\begin{tabular}{|l|l|l|l|}
\hline Severity of stress & No of subjects (\%) & Mean \pm SD & F-value \\
\hline No Stress & $78(52 \%)$ & $29.44 \pm 6.00$ & 36.15 \\
Mild Stress & $50(33.33 \%)$ & $21.84 \pm 6.38$ & P = 0.0001, S \\
Moderate Stress & $14(9.3 \%)$ & $17.25 \pm 2.25$ & \\
Severe Stress & $8(5.3 \%)$ & $16.14 \pm 2.24$ & \\
Total & $150(100 \%)$ & $25.02 \pm 7.55$ & \\
Overall Stress & $72(48 \%)$ & $20.22 \pm 5.97$ & \\
\hline
\end{tabular}

Table 5: Correlation of demographic variables with overall job satisfaction score.

\begin{tabular}{|c|c|c|c|c|}
\hline Demographic Variables & No of subjects & Mean \pm SD & Test Value & P-value \\
\hline Age Group (yrs) & & & F-value & P-value \\
\hline $20-29$ yrs & 79 & $23.65 \pm 6.60$ & \multirow{4}{*}{12.93} & \multirow{4}{*}{$0.0001, \mathrm{~S}$} \\
\hline $30-39$ yrs & 55 & $24.20 \pm 7.23$ & & \\
\hline $40-49$ yrs & 12 & $32.83 \pm 6.42$ & & \\
\hline $50-59$ yrs & 4 & $39.75 \pm 3.20$ & & \\
\hline Gender & & & T-value & P-value \\
\hline Male & 69 & $25.79 \pm 8.32$ & \multirow{2}{*}{1.16} & \multirow{2}{*}{$0.16, \mathrm{NS}$} \\
\hline Female & 81 & $24.35 \pm 6.81$ & & \\
\hline Marital Status & & & T-value & P-value \\
\hline Single & 72 & $23.72 \pm 6.99$ & \multirow{2}{*}{2.04} & \multirow{2}{*}{$0.043, \mathrm{~S}$} \\
\hline Married & 78 & $26.21 \pm 7.88$ & & \\
\hline Years of experience & & & T-value & P-value \\
\hline$<10$ years & 34 & $21.35 \pm 7.57$ & \multirow{2}{*}{3.32} & \multirow{2}{*}{$0.001, \mathrm{~S}$} \\
\hline$\geq 10$ years & 116 & $26.09 \pm 7.23$ & & \\
\hline \multicolumn{3}{|l|}{ Medical Qualification } & F-value & P-value \\
\hline MBBS Only & 19 & $24 \pm 9.51$ & \multirow{3}{*}{1.81} & \multirow{3}{*}{$0.16, \mathrm{NS}$} \\
\hline PG Diploma & 30 & $23.09 \pm 7.92$ & & \\
\hline MD/MS & 101 & $25.83 \pm 6.93$ & & \\
\hline \multicolumn{3}{|l|}{ Working Status } & F-value & P-value \\
\hline PG Students & 61 & $21.38 \pm 6.74$ & \multirow{5}{*}{12.77} & \multirow{5}{*}{$0.0001, \mathrm{~S}$} \\
\hline Senior Residents & 32 & $23.33 \pm 5.12$ & & \\
\hline Asst. Prof & 39 & $22 \pm 7.32$ & & \\
\hline Asso. Prof & 11 & $26.28 \pm 7.06$ & & \\
\hline Professor & 7 & $36.27 \pm 5.69$ & & \\
\hline \multicolumn{3}{|c|}{ Average number of patients seen per day } & F-value & P-value \\
\hline$\leq 10$ & 32 & $25.48 \pm 7.60$ & \multirow{3}{*}{0.79} & \multirow{3}{*}{$0.42, \mathrm{NS}$} \\
\hline $11-50$ & 61 & $25.68 \pm 8.41$ & & \\
\hline$>50$ & 57 & $24.01 \pm 6.47$ & & \\
\hline
\end{tabular}

represented mild stress, 25-29 represented moderate stress, and 30-50 represented severe stress [16]. The questionnaire had also additional questions relating to academic achievement, sources of stress, and any perceived medical illness.

\section{Statistical analysis}

The analysis was done by descriptive and inferential statistics using Chi-square test, One-way ANOVA, student's unpaired t test and multiple logistic regression 
analysis. Data were analyzed using SPSS version 17.0 and $p$-value $<0.05$ considered as significant.

\section{Results}

Among 176 doctors, 16 were excluded because some of them were didn't respond and submitted incomplete forms. Thus, total 150 participants were included in the present study. There were $46 \%$ male and $54 \%$ female doctors with majority of them were married (52\%) and 30 years or older (52\%). Most of them are post graduated $(67.33 \%)$; had more than 10 years of work experience $(77.33 \%)$ and $40 \%$ were seeing around $11-50$ patients per day. Among study participants, $62 \%$ were residents and $38 \%$ were faculties (Table 1 ).

Majority (76\%) of doctors were found to be not satisfied with their job with total job satisfaction low (25.02, sd 7.55). Professional characteristics with least satisfaction were physical working conditions $(2.20 \pm$ $1.12)$, safety and security $(2.07 \pm 1.11)$, workload $(2.07$ $\pm 1.09)$, rate of pay and benefits $(2.19 \pm 1.21)$, professional growth $(2.19 \pm 1.29)$, autonomy $(2.18 \pm 1.24)$ and adequate resources (2.14 \pm 1.22 ) (Table 2 and Table 3 ).

Results also reported that the overall stress among doctors found to be $48 \%$ with mild, moderate and se- vere stress were $33.3 \%, 9.3 \%$ and $5.3 \%$ respectively. Significant correlation was found between severity of stress and total job satisfaction $(p=0.0001)$. As severity of stress increased job satisfaction level decreased (Table 4).

The demographic variables such as age, marital status, years since graduation and working status had significant correlation with job satisfaction $(p<0.05)$; whereas gender, educational status and number of patients seen per day were not significantly correlated ( $p$ $>0.05$ ) (Table 5).

The multiple regression analysis showed that age, educational status and severity of stress were important predictors of job satisfaction among doctors (Table 6).

Factor analysis of job satisfaction characteristics reported in Table 7. KMO measures the sampling adequacy which determines if the responses given with the sample are adequate or not. Kaiser recommend 0.5 as minimum, values between 0.7-0.8 acceptable and values above 0.9 are superb. As shown in Table 7.1, KMO measure is 0.875 , which is higher than 0.5 and therefore can be acceptable. The percentage of variance attributable to each factor after extraction noted in Table 7.2,

Table 6: Multiple Regression Analysis when overall job satisfaction score considered as dependent variable.

\begin{tabular}{|c|c|c|c|c|c|c|c|}
\hline \multirow[t]{2}{*}{ Variables } & \multicolumn{2}{|c|}{$\begin{array}{l}\text { Unstandardized } \\
\text { Coefficients }\end{array}$} & \multirow{2}{*}{$\begin{array}{l}\text { Standardized } \\
\text { Coefficients } \\
\text { Beta }\end{array}$} & \multirow[t]{2}{*}{$\mathbf{t}$} & \multirow[t]{2}{*}{ p-value } & \multicolumn{2}{|c|}{$\begin{array}{l}95.0 \% \text { Confidence Interval } \\
\text { for B }\end{array}$} \\
\hline & B & Std. Error & & & & Lower Bound & Upper Bound \\
\hline Overall Job Satisfaction Score & 31.59 & 4.358 & & & & & \\
\hline Age & 0.37 & 0.094 & 0.320 & 3.958 & $0.0001, \mathrm{~S}$ & 0.185 & 0.555 \\
\hline Gender & -0.70 & 0.911 & -0.047 & 0.779 & $0.438, \mathrm{NS}$ & -2.511 & 1.092 \\
\hline Marital Status & -0.94 & 1.180 & -0.063 & 0.797 & $0.427, \mathrm{NS}$ & -3.273 & 1.392 \\
\hline Year since qualification & -0.56 & 1.393 & -0.032 & 0.406 & $0.685, \mathrm{NS}$ & -3.321 & 2.189 \\
\hline Medical Qualification & -2.22 & 0.811 & -0.210 & 2.741 & $0.007, \mathrm{~S}$ & -3.825 & -0.619 \\
\hline Previous working experience & 0.76 & 0.719 & 0.084 & 1.065 & $0.289, \mathrm{NS}$ & -0.655 & 2.187 \\
\hline Average patients seen & -0.25 & 0.642 & -0.026 & 0.403 & $0.687, \mathrm{NS}$ & -1.529 & 1.011 \\
\hline Severity of stress & -5.77 & 0.624 & -0.653 & 9.259 & $0.0001, \mathrm{~S}$ & -7.008 & -4.542 \\
\hline
\end{tabular}

Table 7.1: KMO and Bartlett's test.

\begin{tabular}{|l|l|l|}
\hline Kaiser-Meyer-Olkin Measure of Sampling Adequacy & $\mathbf{0 . 8 7 5}$ \\
\hline Bartlett's Test of Sphericity & Approx. Chi-Square & 1173.49 \\
\hline & Df & 45 \\
\hline & P-value & $0.0001, \mathrm{~S}$ \\
\hline
\end{tabular}

Table 7.2: Total variance explained.

\begin{tabular}{|c|c|c|c|c|c|c|}
\hline \multirow[t]{2}{*}{ Component } & \multicolumn{3}{|c|}{ Initial Eigen values } & \multicolumn{3}{|c|}{ Extraction Sums of Squared Loadings } \\
\hline & Total & $\%$ of Variance & Cumulative \% & Total & $\%$ of Variance & Cumulative \% \\
\hline 1 & 5.540 & 55.39 & 55.39 & 5.540 & 55.395 & 55.395 \\
\hline 2 & 1.779 & 17.79 & 73.18 & 1.779 & 17.792 & 73.187 \\
\hline 3 & 0.847 & 8.46 & 81.65 & & & \\
\hline 4 & 0.434 & 4.33 & 85.99 & & & \\
\hline 5 & 0.387 & 3.87 & 89.86 & & & \\
\hline 6 & 0.357 & 3.57 & 93.43 & & & \\
\hline 7 & 0.240 & 2.39 & 95.83 & & & \\
\hline 8 & 0.163 & 1.62 & 97.46 & & & \\
\hline 9 & 0.151 & 1.51 & 98.97 & & & \\
\hline 10 & 0.103 & 1.02 & 100.00 & & & \\
\hline
\end{tabular}

Extraction method: Principal component analysis. 
first factor accounts of $55.39 \%$ of the variance and the second $17.79 \%$. All the remaining factors are not significant. This value is of significance to us and therefore we determine in this step that there are two factors which contribute towards why subjects have the overall job satisfaction.

\section{Discussion}

Results of present survey identified $76 \%$ doctors were dissatisfied with their jobs and females were found to be more dissatisfied as compare to males. Khuwaja, et al. in his study among doctors from teaching hospitals of Karachi reported 68\% dissatisfaction with job [3]. While a study among doctors from AlIMS, Delhi showed $69.5 \%$ job satisfaction. Other study by Chaudhury, et al. among doctors identified only $\sim 40 \%$ job satisfaction $[17,18]$. Previous studies also found that females were more dissatisfied compared to males with their profession which are in accordance with our results $[3,7]$. The variations in results of studies could be due to differences among study participants.

It has been observed that physical working conditions; safety and security; workload; rate of pay and benefits; professional growth; autonomy and adequate resources showing least mean score. However, the other professional characteristics such as relations with colleagues; recognition-motivation; and opportunity to use skills and ability showing better score. These findings are almost similar to those reported by Khuwaja, et al. [3]. Whereas study by Sohag AA, et al. demonstrated that "working condition/environment", "pay \& perks" and "work load" were showing least score as compared to "existing service structure", "job prospects", "appreciation/commendation by superiors", "training and development opportunities" and "peer's relationships" [10]. Some other studies attributed increased work load, job insecurity, non-recognition and stressful environment for dissatisfaction [19]. These findings report that professional characteristics influence satisfaction level among doctors.

The increase in age showed consistent increase in job satisfaction level with age being significantly correlated with overall satisfaction. Previous literature also indicated that job satisfaction showed positive correlation with increase in age $[20,21]$. While other study reported high satisfaction level among young doctors which fell abruptly after the age of 35 years and to rise again in fifth and sixth decade of life [17]. Doctors with $>10$ years' experience found to have high job satisfaction level with duration of experience being significantly associated with overall satisfaction. Previous literature also noticed that a large proportion of doctors expressed satisfaction when they just joined the profession, followed by significant fall in satisfaction level after they put in 5 to 10 years of service, and subsequently gradual increase over another decade or so [17].
Married doctors found to be more satisfied than unmarried one with marital status being significantly associated with job satisfaction. It could be hypothesized that good support helps in coping stressful situation and further lead to increase in satisfaction level. Doctors working as PG students and Senior Residents had higher dissatisfaction as comparison to those on post of Assistant Professor, Associate Professor and Professor with designation being significantly associated with total job satisfaction. Above findings are similar to results shown by Sohag AA, et al. in his study. This could be due to the fact that professors are having their peak designation related salary [10].

The other variables such as gender, educational status and number of patients seen per day had no significant association with job satisfaction level with comparatively more dissatisfaction among female participants, those with lowest educational status and more patients seen per day. Previous studies found that doctors who had more than 8 work hours per day and more night shifts were found to be more dissatisfied [22-24]. More dissatisfaction among doctors with lowest qualifications has also been reported $[6,10]$. These findings are almost similar to our study results.

The present study identified high prevalence of stress (48\%) among doctors with significant difference for overall job satisfaction. There found to be negative correlation between job satisfaction and stress level $(r=$ $-0.612, p$-value $=0.0001$ ). Past studies also found more stress level among doctors and many of them reported that job stress affects their physical as well as mental health $[3,25]$. Job stress leads to poor performance at workplace, poor quality of care, and difficulties in caring for patients, spending adequate time with patients and continuing good relationships $[26,27]$.

This study reported age, educational status and severity of stress were potential influential factors for total job satisfaction among doctors. Ghazali, et al. found that service structure and low income were main factors contributing to job dissatisfaction [6]. Sohag AA, et al. identified that working environment; pay/perks and workload were important factors for job dissatisfaction [10]. These variations could be attributed to differences in study population; different variables and tools used; and cultural differences. So, it can be advised to focus on these issues to elaborate risk or influential factors for job satisfaction in future research.

\section{Strengths and Limitations}

1. We selected doctors directly involved with patients care provision including PG trainees and faculties which is strength of our study.

2. We have included doctors from one medical college only and the sample size is small. Hence the results cannot be generalized. 


\section{Conclusion}

Majority of doctors were found to be unsatisfied with job and had more stress among them. Factors like age, educational status and severity of stress emerged as potential influential factors. Workload; pay and benefits; autonomy; safety and security; and workload were associated with more dissatisfaction. So, these factors should be addressed by institutional authority to raise job satisfaction among doctors, improve health care delivery, retention of faculties in college, to reduce stress level, to provide safety, to decrease workload and sufficient autonomy. The results of present study can help in future studies to identify the measures for improving satisfaction among doctors by addressing the identified risk factors.

\section{References}

1. Michie S (2002) Causes and management of stress at work. Occup Environ Med 59: 67-72.

2. Spector PE (1997) Job satisfaction. Sage publication, thousand oaks, CA, USA.

3. Khuwaja AK, Qureshi R, Andrades M, Fatmi Z, Khuwaja NK (2004) Comparison of job satisfaction and stress among male and female doctors in teaching hospitals of Karachi. $J$ Ayub Med Coll Abottabad 16: 23-27.

4. Guion RM (2005) Industrial morale: The problem of terminology in personnel psychology. ( $2^{\text {nd }}$ edn), London, 59-64.

5. Janus K, Amelung VE, Baker LC, Gaitanides M, Schwartz FW, et al. (2008) Job satisfaction and motivation among physicians in academic medical centers: insights from a cross-national study. J Health Polit Policy Law 33: 11331167.

6. Ghazali SA, Shah IA, Zaidi SA, Tahir MH (2007) Job satisfaction among doctors working at teaching hospital of bahawalpur, pakistan. J Ayub Med College Abbottabad 19: 44-45.

7. Kaur S, Sharma R, Talwar R, Verma A, Singh S (2009) A study of job satisfaction and work environment perception among doctors in a tertiary hospital in Delhi. Indian J Med Sci 63: 139-144.

8. Speakman HG, Pleasant JM, Sutton GB (1996) The job satisfaction of physical therapists. Physiother Res Int 1 : 247-254.

9. Akroyd D, Wilson S, Painter J, Figuers C (1994) Intrinsic and extrinsic predictors of work satisfaction in ambulatory care and hospital settings. J Allied Health 23: 155-164.

10. Sohag AA, Memon S, Mahmood-Ur-Rahman, Rao MH (2012) A comparative study on factors causing job dissatisfaction among serving doctors at teaching hospitals of $\mathrm{Hy}$ derabad, Pakistan. Pak J Med Sci 28: 710-715.

11. Blenkin H, Deary IJ, Sdler A, Agius R (1996) Stress in NHS consultants. BMJ 310: 534 .

12. Ramirez AJ, Graham J, Richards MA, Cull A, Gregory WM (1996) Mental health of hospital consultants: the effects of stress and satisfaction at work. Lancet 347: 724-728.

13. Kapur N, Borrill C, Stride C (1998) Psychological morbidity and job satisfaction in hospital consultants and junior house officers: Multicentre, cross sectional survey. BMJ 317: 511512.
14. Lindeman S, Laara E, Hakko H, Lonnqvist J (1996) A systematic review on gender-specific suicidal mortality in medical doctors. Br J Psychiatry 168: 274-279.

15. Murray RM (1976) Alcoholism amongst male doctors in Scotland. Lancet 308: 729-733.

16. Andrews G, Slade T (2001) Interpreting score on the kessler psychological distress scale (K10). Aust N Z J Public Health 25: 494-497.

17. Nirpuma Madaan (2008) Job satisfaction among doctors in a tertiary care teaching hospital. JK Science 10: 81-83.

18. Chaudhury S, Bannerjee A (2004) Correlates of job satisfaction in medical officers. MJAFI 60: 329-332.

19. Firth-Cozens $J$ (2001) Cultures for improving patient safety through learning: the role of teamwork. Qual Health Care 10: $26-31$.

20. Magne Nylenna, Pål Gulbrandsen, Reidun Førde, Olaf G Aasland (2005) Unhappy doctors? A longitudinal study of life and job satisfaction among norwegian doctors 19942002. BMC Health Services Research 5: 44.

21. Al-Eisa IS, Al-Muttar MS, Al-Abduljalil HK (2005) Job satisfaction of primary health care physicians at primary health care region, Kuwait. MEJM 3: 3.

22. Appleton K, House A, Dowell A (1998) A survey of job satisfaction, sources of stress and psychological symptoms among general practitioners in leeds. Bir J Gen Pract 48: 1049-1063.

23. Brondt A, Vedsted P, Olesen F (2007) General practitioners' job satisfaction. Ugeskr laeger 169: 2521-2525.

24. Sehlen S, Vordermark D, Schafer C, Herschbach P, Bayerl A, et al. (2009) Job stress and job satisfaction of physicians, radiographers, nurses and physicists working in radiotherapy: a multicenter analysis by the degro quality of life work group. Radiat Oncol 4: 6 .

25. Gobbur SB, Nigudgi SR, Reddy S (2016) Prevalence of stress among post graduate doctors at mahadevappa rampure medical college kalaburagi, karnataka. Int J Community Med Public Health 3: 576-580.

26. Firth-Cozens J, Greenhalgh J (1997) Doctors' preceptions of the links between stress and lowered clinical care. Soc Sci Med 44: 1017-1022.

27. Devoe Jennifer, Fryer Jr GE, Hargraves JL, Phillips RL, Green LA (2002) Does career dissatisfaction affects the ability of family physicians to deliver high-quality patient care? J Fam Pract 51: 223-228. 